\title{
The Equation of Meshing of Spiral Bevel Gears Manufactured by Generating-Line Method
}

\author{
Yankun Wang ${ }^{*}$, Zhaojun Yang, Linan Li and Xuecheng Zhang \\ School of Mechanical Science and Engineering, Jilin University, Changchun, 130025, China
}

\begin{abstract}
The theory of generating-line method has been discussed in this study. It is a new theory of manufacturing spiral bevel gears of which tooth surfaces are formed by exact spherical involutes. The tooth surface of spiral bevel gears is obtained by the pure-rolling motion between the base cone and the great circular plane of the fundamental sphere. Based on the cutting motions the equations to describe tooth surfaces have been derived by using theory of gearing, and the equation of meshing of spiral bevel gears with spherical involute tooth surface is obtained in the text. This study can provide some fundamentals for manufacturing and contact analysis of spherical involute spiral bevel gears.
\end{abstract}

Keywords: Equations of meshing, generating-line, spiral bevel gears.

\section{INTRODUCTION}

Spiral bevel gears are widely used for intersecting shafts, they are the most efficient means of transmitting rotations between intersecting shafts. Design and manufacturing of such gear drives has been a topic of research [1-4]. In most of the current work, the tooth profile of spiral bevel gear manufactured by exclusive machines is not a spherical involute curve, the tooth-surface geometry is analyzed by expanding on the planar involute geometry [5]. The companies like Gleason Works and Klingelnberg-Oerlikon have developed advanced technology and equipments for manufacturing the spiral bevel gears, but there are still some disadvantages: the cutting machines are expensive, the gear ratio is not constant during the tooth engagement cycle [6], in order to reduce the kinematical errors and transmission errors the complicated machine tool settings are needed [7]. Tooth Contact Analysis computer program for simulation of meshing and contact of gear drive has been used to enhance the meshing quality $[8,9]$.

The spiral bevel gears with spherical involutes tooth profile have many good properties such as the interchangeability and the constant ratio of angular speed [10]. Tsai and Chin described the tooth-surface of bevel gears by a family of spherical involutes curves initiating from a radial straight line on the base cone [11]. A suitable formulation and its implementing algorithms have been proposed for involute and octoidal bevel-gear generation [12]. A solid model of straight and spiral bevel gears were obtained by using simple sweeping techniques to their tooth profiles described by the exact spherical involutes [13].

In this paper the spiral bevel gears with exact spherical involutes tooth profile can be obtained by generating-line method. The equations of tooth surfaces and the equation of meshing of spiral bevel gears with spherical involutes tooth

*Address correspondence to this author at the School of Mechanical Science and Engineering, Jilin University, Changchun, 130025, China; Tel: +860431- 85095839(office), +86-13504431691 (Mobile); Fax: +86-043185095839; E-mails: wyk@jlu.edu.cn,147082753@qq.com profile are deduced based on the cutting moment and the theory of gearing. It is the foundation of design, manufacture and contact analysis of spherical involutes spiral bevel gears.

\section{THE BASICS OF GENERATING-LINE METHOD}

The exact spherical involutes can be obtained by the pure-rolling motion between the base cone and the great circle of the fundamental sphere. The generating process of exact spherical involutes is shown in Fig. (1). The arc TP is the spherical involute traced by a point $\mathrm{P}$ of the great circle $\mathrm{C}$ during the pure-rolling motion of its disk plane on the base cone. The principle of surfaces generated by generating-line method is shown in Fig. (2). S is an arc in the plane Q. The plane $\mathrm{Q}$ and the base cone in tangency along line OJ, $\delta_{\mathrm{b}}$ is the base cone angle. In order to keep the pure-rolling motion between them, plane $\mathrm{Q}$ and the base cone rotate with their respective angular velocities $\omega_{\mathrm{q}}$ and $\omega$, the relation between $\omega$ and $\omega_{\mathrm{q}}$ is described as,

$$
\omega_{q} / \omega=\sin \delta_{b}
$$

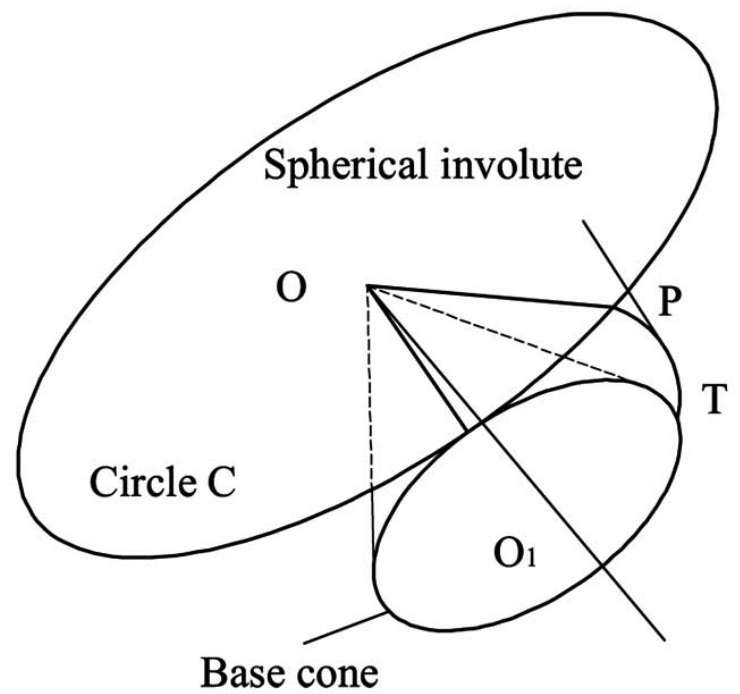

Fig. (1). Generation of the exact spherical involute. 


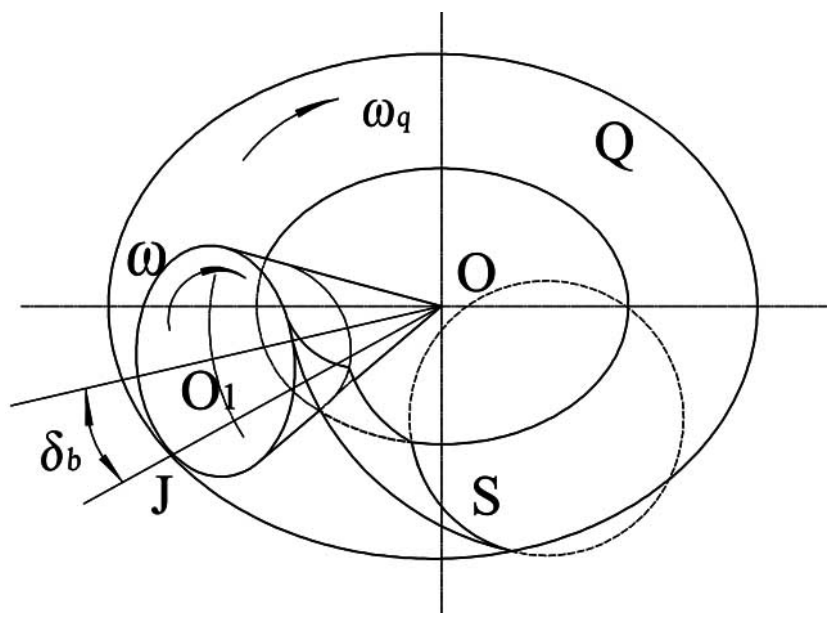

Fig. (2). Generation of the tooth surface formed by spherical involutes.

When the arc S on the plane Q rotates together with plane $\mathrm{Q}$ to keep pull-rolling motion with the base cone, the trace of the arc $\mathrm{S}$ should be a right-hand concave tooth surface formed by a family of exact spherical involutes. If the cutting edge on the plane $\mathrm{Q}$ shaped identical to the generating line $\mathrm{S}$ keeps pull-rolling with the base cone, and rotates about its geometrical center to enhance the cutting velocity simultaneity, the surface is obtained [14].

\section{COORDINATE SYSTEMS AND EQUATIONS OF THE SURFACES}

The equation of meshing is the fundamental starting point for developing the computerized gear design and meshing quality. In order to deriving the equation of meshing, the equation of tooth surface should be deduced. So the coordinate systems should be set up firstly.

Coordinate systems applied are shown in Fig. (3). Coordinate system $S=[O ; X, Y, Z]$ is the fixed one which origin $\mathrm{O}$ coincidence with the center of $\mathrm{Q}$ plane, the common tangent of the plane $\mathrm{Q}$ and the base cone 1 is defined as axis $\mathrm{OX}$, the axis $\mathrm{OZ}$ is perpendicular to $\mathrm{Q}$ plane, the axis $\mathrm{OY}$ in $\mathrm{Q}$ plane is perpendicular to $\mathrm{OX}$ and $\mathrm{OZ}$. The coordinate system of gear 1 is set up like this: $S_{1}=\left[O ; X_{1}, Y_{1}, Z_{1}\right]$ is connected to the base cone of gear $1, \mathrm{OX}_{1}$ in the coordinate plane $\mathrm{O}-\mathrm{XZ}$ is designed to represent the rotary axis of base cone $1, \mathrm{OY}_{1}$ coincides with $\mathrm{OY}$, the angle between axis $\mathrm{OX}$ and axis $\mathrm{OX}_{1}$ labeled $\delta_{b 1}$ is denoted as the base angle of gear 1. Coordinate system $S_{f}=\left[O ; X_{f}, Y_{f}, Z_{f}\right]$ is an auxiliary coordinate system of which the axis $\mathrm{OZ}_{\mathrm{f}}$ coincides with $\mathrm{OZ}$, they are all perpendicular to plane $\mathrm{O}-\mathrm{XY}$, and $\alpha$ denoted as the angle between $\mathrm{OX}_{\mathrm{f}}$ and $\mathrm{OX}$, axis $\mathrm{OX}_{\mathrm{f}}$ is the common tangent of $\mathrm{Q}$ plane and cone 2 . The coordinate system $S_{2}=\left[O ; X_{2}, Y_{2}, Z_{2}\right]$ is connected to the base cone of gear 2 , $\mathrm{OX}_{2}$ is the rotary axis of base cone 2, the angle between axis $\mathrm{OX}_{2}$ and axis $\mathrm{OX}_{\mathrm{f}}$ labeled $\delta_{b 2}$ is denoted as the base angle of gear 2, $\mathrm{OY}_{2}$ coincides with $\mathrm{OY}_{\mathrm{f}}$ in $\mathrm{Q}$ plane. Fig. (4) shows the relationship between coordinate systems $S_{q}$ and $S_{d}$.
Coordinate system $S_{q}=\left[O ; X_{q}, Y_{q}, Z_{q}\right]$ is a moving coordinate system, it is coincidence with the fixed coordinate system $\mathrm{S}$ at the beginning, then rotated about the axis $\mathrm{OZ}$ with the angular velocities of $\omega_{q}$ with plane $Q$, the angle $\phi$ between $\mathrm{OX}_{\mathrm{q}}$ and $\mathrm{OX}$ is denoted by $\omega_{q} t$. Coordinate system $S_{d}=\left[O ; X_{d}, Y_{d}, Z_{d}\right]$ is connected to the arc generating line, the origin $\mathrm{O}_{\mathrm{d}}$ is the center of the arc whose position is denoted by length $b$ and angle between $\mathrm{OY}_{\mathrm{d}}$ and $\mathrm{OY}_{\mathrm{q}}$ labeled $\beta$. The generating line is an arc with the radius $r_{\mathrm{d}}$, in coordinate system $\mathrm{S}_{\mathrm{q}}$, the generating line can be represented by,

$r_{q}=\left[\begin{array}{c}r_{d} \cos (\beta+\theta)-b \sin \beta \\ r_{d} \sin (\beta+\theta)+b \cos \beta \\ 0\end{array}\right]$

Here, $\theta$ is the parameter of the generating line.

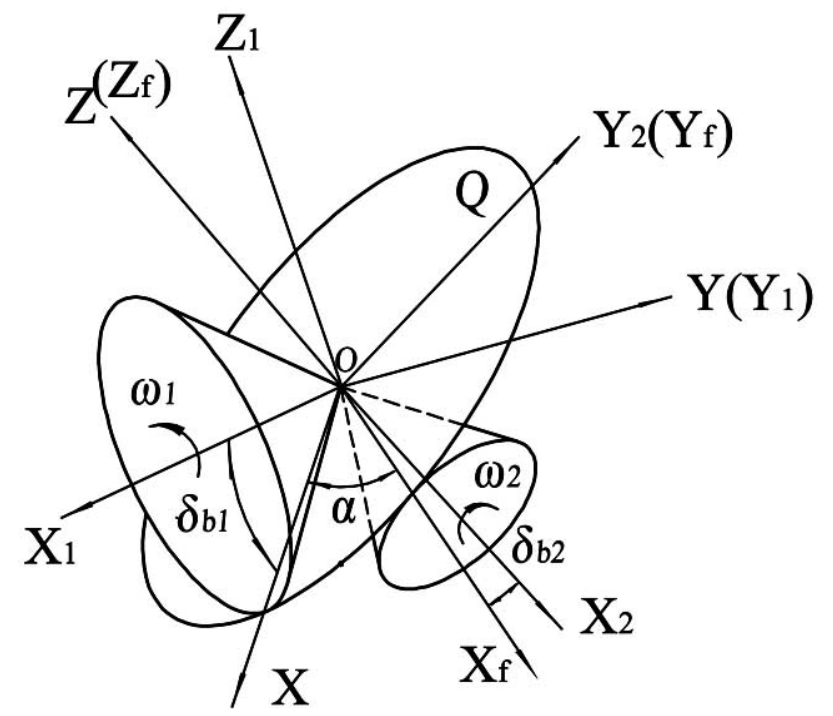

Fig. (3). Coordinate systems.

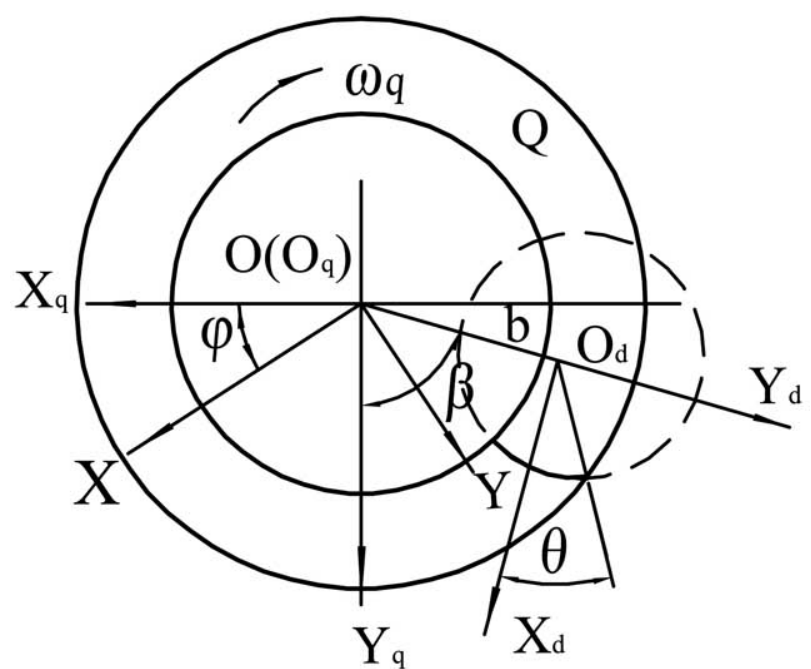

Fig. (4). Coordinate system of generating line.

In coordinate system $\mathrm{S}_{1}$ the equation of surface $r_{1}$ is represented by, 


$$
r_{1}(\theta, \phi)=x_{1} i_{1}+y_{1} j_{1}+z_{1} k_{1}
$$

Here,

$$
\begin{aligned}
A= & \phi-\beta \\
x_{1}= & \cos \delta_{b 1}\left[r_{d} \cos (A-\theta)+b \sin A\right] \\
y_{1}= & \cos \psi_{1}\left[-r_{d} \sin (A-\theta)+b \cos A\right]+\sin \psi_{1} \sin \delta_{b 1} \\
& {\left[r_{d} \cos (A-\theta)+b \sin A\right] } \\
z_{1}= & \sin \psi_{1}\left[-r_{d} \sin (A-\theta)+b \cos A\right]-\cos \psi_{1} \sin \delta_{b 1} \\
& {\left[r_{d} \cos (A-\theta)+b \sin A\right] }
\end{aligned}
$$

And, $\psi_{1}=\phi / \sin \delta_{b 1}$.

In coordinate system $\mathrm{S}_{2}$ the equation of surface $r_{2}$ is represented by,

$$
r_{2}(\theta, \phi)=x_{2} i_{2}+y_{2} j_{2}+z_{2} k_{2}
$$

Here,

$$
\begin{aligned}
B= & \phi-\beta+\alpha \\
x_{2}= & \cos \delta_{b 2}\left[r_{d} \cos (B-\theta)+b \sin B\right] \\
y_{2}= & \cos \psi_{2}\left[-r_{d} \sin (B-\theta)+b \cos B\right]+\sin \psi_{2} \sin \delta_{b 2} \\
& {\left[r_{d} \cos (B-\theta)+b \sin B\right] } \\
z_{2}= & -\sin \psi_{2}\left[-r_{d} \sin (B-\theta)+b \cos B\right]+\cos \psi_{2} \sin \delta_{b 2} \\
& {\left[r_{d} \cos (B-\theta)+b \sin B\right] }
\end{aligned}
$$

And, $\psi_{2}=\phi / \sin \delta_{b 2}$.

The expression of unit normal vector of surface $r_{1}$ in coordinate system $\mathrm{S}_{1}$ is represented by,

$$
n_{1}=n_{\mathrm{t}} i_{1}+n_{\mathrm{y}} j_{1}+n_{\mathrm{z}} k_{1}
$$

Here,

$$
\begin{aligned}
& n_{x 1}=\cos \delta_{b 1} \cos (A-\theta) \\
& n_{y 1}=-\cos \psi_{1} \sin (A-\theta)+\sin \delta_{b 1} \sin \psi_{1} \cos (A-\theta) \\
& n_{z 1}=-\sin \psi_{1} \sin (A-\theta)-\sin \delta_{b 1} \cos \psi_{1} \cos (A-\theta)
\end{aligned}
$$

\section{EQUATION OF MESHING}

The concept of relative velocity is used for the derivation of the equation of meshing. According to the theory of gearing, consider the two gears are rotated about crossed axes with angular velocities $\omega_{1}$ and $\omega_{2}$, respectively, the conjugated points $\mathrm{N}_{1}$ and $\mathrm{N}_{2}$ are the points of gear tooth surfaces $r_{1}$ and $r_{2}$. When the two gears rotated, points $\mathrm{N}_{1}$ and $\mathrm{N}_{2}$ coincidences at point $\mathrm{N}$. The relative velocity $V^{12}$ of point $\mathrm{N}_{1}$ of gear 1 with respect to point $\mathrm{N}_{2}$ of gear 2 can be represented by the equation,

$V^{12}=\omega^{12} \times r$

Here $r$ is the position vector that is drawn to contact point in the fixed coordinate system, which is described by,

$$
r=x i+y j+z k
$$

The surface equation and normal vector of $r_{1}$ are represented in coordinate system $\mathrm{S}_{1}$, they should be determined in the fixed coordinate system $\mathrm{S}$. The transformational matrix from $S_{1}$ to $S$ is represented by,

$$
M_{s 1}=\left[\begin{array}{ccc}
\cos \delta_{b 1} & 0 & -\sin \delta_{b 1} \\
0 & 1 & 0 \\
\sin \delta_{b 1} & 0 & \cos \delta_{b 1}
\end{array}\right]
$$

When gear 1 rotated with angle $\phi_{1}$, gear 2 rotated with angle $i_{21} \phi_{1}$, the rotational matrix of coordinate system $\mathrm{S}_{1}$ rotated about axis $\mathrm{OX}_{1}$ is represented by,

$$
M_{\varphi 1}=\left[\begin{array}{ccc}
1 & 0 & 0 \\
0 & \cos \varphi_{1} & -\sin \varphi_{1} \\
0 & \sin \varphi_{1} & \cos \varphi_{1}
\end{array}\right]
$$

Therefore, the expression of vector of meshing point in fixed coordinate system is represented by,

$$
r=M_{\varphi 1} M_{s 1} r_{1}=x i+y j+z k
$$

Here,

$$
\begin{aligned}
& x=\cos \delta_{b 1} x_{1}-\sin \delta_{b 1} z_{1} \\
& y=\cos \phi_{1} y_{1}-\sin \phi_{1}\left(\sin \delta_{b 1} x_{1}+\cos \delta_{b 1} z_{1}\right) \\
& z=\sin \phi_{1} y_{1}+\cos \phi_{1}\left(\sin \delta_{b 1} x_{1}+\cos \delta_{b 1} z_{1}\right)
\end{aligned}
$$

The relative angular velocity $\omega^{12}$ should be deduced. The gear ratio $i_{21}$ is represented by the equation,

$$
i_{21}=\frac{\omega_{2}}{\omega_{1}}
$$

The angular velocity $\omega_{1}$ and $\omega_{2}$ are shown in Fig. (3). Conveniently, consider $\omega_{1}=1$, then $\omega_{2}=i_{21}$. In fixed coordinate system $\omega_{1}$ and $\omega_{2}$ can be represented as,

$$
\begin{aligned}
& \omega_{1}^{S}=\left[\begin{array}{lll}
\cos \delta_{b 1} & 0 & \sin \delta_{b 1}
\end{array}\right]^{T} \\
& \omega_{2}^{S}=\left[\begin{array}{llll}
-i_{21} \cos \delta_{b 2} \cos \alpha & i_{21} \cos \delta_{b 2} \sin \alpha & i_{21} \sin \delta_{b 2}
\end{array}\right]^{T}
\end{aligned}
$$

Thus, the expression for $\omega^{12}$ can be represented in fixed coordinate system as,

$$
\omega^{12}=\omega_{1}^{S}-\omega_{2}^{S}=\left[\begin{array}{c}
\cos \delta_{b 1}+i_{21} \cos \delta_{b 2} \cos \alpha \\
-i_{21} \cos \delta_{b 2} \sin \alpha \\
\sin \delta_{b 1}-i_{21} \sin \delta_{b 2}
\end{array}\right]
$$

Then, subscribed (15), (20) into (11), the relative velocity $V^{12}$ is represented in fixed coordinate system by the following expressions:

$$
\begin{aligned}
& V_{x}^{12}=-z i_{21} \cos \delta_{b 2} \sin \alpha-y\left(\sin \delta_{b 1}-i_{21} \sin \delta_{b 2}\right) \\
& V_{y}^{12}=-z\left(\cos \delta_{b 1}+i_{21} \cos \delta_{b 2} \cos \alpha\right)+x\left(\sin \delta_{b 1}-i_{21} \sin \delta_{b 2}\right) \\
& V_{z}^{12}=y\left(\cos \delta_{b 1}+i_{21} \cos \delta_{b 2} \cos \alpha\right)+x i_{21} \cos \delta_{b 2} \sin \alpha
\end{aligned}
$$


According to the theory of gearing, in the fixed coordinate system the equation of meshing of the surfaces is represented by equation,

$$
\varphi(\theta, \phi, t)=n \cdot V^{12}=n_{x} V_{x}^{12}+n_{y} V_{y}^{12}+n_{z} V_{z}^{12}=0
$$

And in fixed coordinate system, the unit normal vector of meshing point is represented by equation,

$$
n=M_{\varphi 1} M_{s 1} n_{1}=n_{x} i+n_{y} j+n_{z} k
$$

Here,

$$
\begin{aligned}
& n_{x}=\cos \delta_{b 1} n_{x 1}-\sin \delta_{b 1} n_{z 1} \\
& n_{y}=\cos \varphi_{1} n_{y 1}-\sin \varphi_{1}\left(\sin \delta_{b 1} n_{x 1}+\cos \delta_{b 1} n_{z 1}\right) \\
& n_{z}=\sin \varphi_{1} n_{y 1}+\cos \varphi_{1}\left(\sin \delta_{b 1} n_{x 1}+\cos \delta_{b 1} n_{z 1}\right)
\end{aligned}
$$

Subscribed (21), (24) into (22), then obtained the expression of meshing equation in fixed coordinate system as follows:

$$
U \cos \phi_{1}-V \sin \phi_{1}=W
$$

Here,

$$
\begin{aligned}
U= & {\left[-z\left(\cos \delta_{b 1}+i_{21} \cos \delta_{b 2} \cos \alpha\right)+x\left(\sin \delta_{b 1}-i_{21} \sin \delta_{b 2}\right)\right] n_{y 1} } \\
& +\left[y\left(\cos \delta_{b 1}+i_{21} \cos \delta_{b 2} \cos \alpha\right)+x i_{21} \cos \delta_{b 2} \sin \alpha\right] \\
& \left(\sin \delta_{b 1} n_{x 1}+\cos \delta_{b 1} n_{z 1}\right) \\
V= & {\left[-z\left(\cos \delta_{b 1}+i_{21} \cos \delta_{b 2} \cos \alpha\right)+x\left(\sin \delta_{b 1}-i_{21} \sin \delta_{b 2}\right)\right] } \\
& \left(\sin \delta_{b 1} n_{x 1}+\cos \delta_{b 1} n_{z 1}\right)-\left[y\left(\cos \delta_{b 1}+i_{21} \cos \delta_{b 2} \cos \alpha\right)\right. \\
& \left.+x i_{21} \cos \delta_{b 2} \sin \alpha\right] n_{y 1} \\
W= & -\left[-z i_{21} \cos \delta_{b 2} \sin \alpha-y\left(\sin \delta_{b 1}-i_{21} \sin \delta_{b 2}\right)\right] \\
& \left(\cos \delta_{b 1} n_{x 1}-\sin \delta_{b 1} n_{z 1}\right)
\end{aligned}
$$

When $i_{21}$ and $\delta$ are given, the values of $U, V, W$ only relate to the position of meshing point $\left(\mathrm{x}_{1}, \mathrm{y}_{1}, \mathrm{z}_{1}\right), U, V, W$ are the function of $\theta$ and $\varphi$. Thus, when the position of meshing point is given, the rotate angle $\phi_{1}$ which is the function of $\theta$ and $\varphi$ can be calculated by equation of meshing. It is represented by equation,

$$
\phi_{1}=\arccos \left(\frac{W}{\sqrt{U^{2}+V^{2}}}\right)-\arctan \left(\frac{V}{U}\right)
$$

From the equation above, it showed that a set of values of $\theta$ and $\varphi$ determined the values of $\phi_{1}$, it means that when the gear rotated with angles $\phi_{1}$, the correspondence of point determined by $\theta$ and $\varphi$ becomes the meshing point. If the surfaces are line contact, the certain contact line exists. Generally, when considering the value of parameter $t$ is $t_{0}$, the equation of instantaneous contact line is represented by equations,

$$
\left\{\begin{array}{l}
\phi\left(\theta, \varphi, t_{0}\right)=0 \\
r_{1}=r_{1}(\theta, \varphi)
\end{array}\right.
$$

\section{CONCLUSIONS}

Generating-line method is a new method of designing and manufacturing spiral bevel gears with spherical involute tooth profile. The spiral bevel gears manufactured by generating-line method can avoid errors caused by using the planer involute tooth profile on the back cone to replace the spherical involute tooth profile. The tooth surface formed by spherical involutes has been obtained by making the cutting edge shape be identical to the generating line which is arc or line. This kind of spiral bevel gear has many advantages, the structure of machine and the cutting motions are not so complicated.

The equations of tooth surfaces which describe the new kind of spiral bevel gears have been deduced, and the equations of meshing which provide the foundations for the design, modeling and contact analysis of this kind of spiral bevel gears are obtained.

\section{ACKNOWLEDGEMENTS}

The author would like to thank the Research Fund for the Doctoral Program of Higher Education of China (Grant No. 20090061110023), the Key Program of technology development of Jilin province (Grant No. 20080346) and Graduate Innovation Fund of Jilin University (Grant No. 20101019) for their financial support of the research.

\section{REFERENCES}

[1] F. L. Litvin, A. Fuentes, and K. Hayasaka, "Design, manufacture stress analysis, and experimental tests of low-noise high endurance spiral bevel gears", Mech. Mach. Theory, vol. 41, pp. 83-118, January 2006.

[2] Y. C. Tsai, and W. Y. Hsu, "The study on the design of spiral bevel gear sets with circular-arc contact paths and tooth profiles", Mech. Mach. Theory, vol. 43, pp. 1158-1174, September 2008.

[3] J. Argyris, A. Fuentes, and F. L. Litvin, "Computerized integrated approach for design and stress analysis of spiral bevel gears", Comput. Methods Appl. Mech. Eng., vol. 191, pp. 1057-1095, 2002.

[4] A. Fuentes, F. L. Litvin, B. R. Mullins, R. Woods, and R. F. Handschuh, "Design and stress analysis of low-noise adjusted bearing contact spiral bevel gears", J. Mech. Des., vol. 124, pp. 524-532, September 2002.

[5] F. L. Huston, and J. J. Coy, "Surface geometry of circular cut spiral bevel gears", J. Mech. Des., vol. 104, pp. 743-748, October 1982.

[6] F. L. Litvin, and A. Fuentes, Gear Geometry and Applied Theory, Cambridge University Press, USA 2004.

[7] V. V. Simon, "Design and manufacture of spiral bevel gears with reduced transmission errors", J. Mech. Des. Trans. AsME, Vol. 131, pp. 0410071-04100711, 2009.

[8] F. L. Litvin, A. Fuentes, Q. Fan, and R. F. Handschuh, "Computerized design, simulation of meshing, and contact and stress analysis of face-milled formate generated spiral bevel gears", Mech. Mach. Theory, vol. 37, pp. 441-459, May 2002.

[9] F. L. Litvin, M. De Donno, A. Peng, A. Vorontsov, and R. F. Handschuh, "Integrated computer program for simulation of meshing and contact of gear drives", Comput. Methods in Appl. Mech. Eng., vol. 181, pp. 71-85, January 2002.

[10] G.. Figliolini, and J. Angeles, "Algorithms for involute and octoidal bevel-gear generation", J. Mech. Des., vol. 127, pp. 664-672, July 2005.

[11] Y. C. Tsai, and P. C. Chin, "Surface geometry of straight and spiral bevel gears", J. Mech. Transm. Autom. Des., vol. 109, pp. 443-449, December 1987.

[12] H. W. Lee, K. O, Lee, and D. H. Chung, "A kinematic investigation of a spherical involute bevel-geared system", Proc. IMechE Part C: J. Mech. Eng. Sci., vol. 224, pp. 1335-1348, 2009. 
[13] M. J. Al-Daccak, J. Angeles, and M. A. González-Palacios, "The modeling of bevel gears using the exact spherical involute", $A S M E$ J. Mech. Des., vol. 116, pp. 364-368, 1994.
[14] F. H. Peng, Involute Gear Cutting on the Tracing Line, Jilin Science and Technology Press, China, 2008. (In Chinese)

(C) Wang et al.; Licensee Bentham Open.

This is an open access article licensed under the terms of the Creative Commons Attribution Non-Commercial License (http: //creativecommons.org/licenses/by$\mathrm{nc} / 3.0 /$ ), which permits unrestricted, non-commercial use, distribution and reproduction in any medium, provided the work is properly cited. 